\title{
Regulating Affective Involvement in In-Session Verbal Interaction by Shifting Perspective: A Longitudinal Study of One Client-Therapist Dyad in Psychodynamic Psychotherapy
}

\author{
Eszter Berán ${ }^{1}$ \\ Pázmány Péter Catholic University, Institute of Psychology \\ Czobor Pál \\ Semmelweis University, Psychiatric and Psychotherapy Clinic \\ Unoka Zsolt \\ Semmelweis University, Psychiatric and Psychotherapy Clinic
}

\begin{abstract}
Our study examined in-session affect regulation as a self-regulatory process as well as a process of interpersonal regulation during the psychoanalytical therapeutic session. We used a novel approach for studying affective involvement by analyzing narrative perspective (NP) taken by client and analyst. In a longitudinal study of 18 months we observed the interaction of one client - therapist dyad during the psychoanalytic session in the early and working phases of psychotherapy. Transcribed sessions were segmented into intonation units, and participants' use of NP was then coded for each intonation unit line based on six linguistic variables shown to signal affective involvement in earlier studies: verb tense, subject number and person, diegesis, focalization, and discourse level. We found that affective involvement on the part of both speakers was higher at the working phase. The client's involvement was higher than the therapist's. We describe an affect-regulation cycle characteristic of the interaction. Our approach proves to be useful in analyzing regulation of affective involvement and its long term change. Differences were detectable in the self and interactive regulatory strategies of affective involvement.
\end{abstract}

\section{Introduction}

Affect regulation in the psychotherapeutic setting has been linked to effective treatment outcomes (Bradley, 2003; Sloan \& Kring, 2007; Watson, McMullen, Prosser, \& Bedard, 2011) in various forms of psychotherapies. By affect regulation following Watson and colleagues (Watson et al., 2011) — we mean the capability to process, modulate, and express affective experience. In-session affect regulation has been measured based on verbatim transcriptions of the therapeutic session-among other methods - showing that affectively rich and less emotional but rather abstract,

${ }^{1}$ Correspondence concerning this article should be addressed to Eszter Berán, Department of Developmental and Clinical Child Psychology, Pázmány Péter Catholic University, Budapest, Hungary, 1088 Budapest, Mikszáth tér. 1. Email: eszter_beran@yahoo.com 
reflective sequences of talk during the psychoanalytic session differ in terms of their function in the therapeutic process (Mergenthaler, 1996; Buchheim \& Mergenthaler, 2000; Bucci, 1995; Bucci, 2001; Thoma \& Kachele, 2006). Affective involvement and regulation strategies of client and therapist may also change from the beginning of treatment over time, predicting, for example, emotional processing during working phases of therapy as well as outcome (Watson et al., 2011; Berking et al., 2008). The purpose of the current study is to introduce a novel method for examining regulation of affective involvement during the psychoanalytic session. We assess affective involvement by examining structural characteristics of self-narratives jointly constructed by client and analyst during the session, based on the full verbatim transcripts of talk. We show how change in regulation of affective involvement can be assessed in the talk of one client-therapist dyad at two therapy sessions taking place 18 months apart, one from the beginning, and one from the working phase of treatment. We compare sessions by analyzing shifts in narrative perspective (NP) of the speakers.

$\mathrm{NP}$ is the point of view from which the narrator presents actions, events, and characters of the narrative to listeners (Genette \& Lewin, 1983; Uspensky, 1973). Previous studies have shown that linguistically based aspects of NP - for instance verb tense, subject number or person - vary in terms of expressing emotional involvement of the narrator (Schiffrin, 1981; Wolfson, 1979; Tannen, 1989; McIsaac \& Eich, 2002; McIsaac \& Eich, 2004; Sutin \& Robins, 2008). Since NP of speakers shifts continuously during interaction (Uspensky, 1973; Chafe, 1994), levels of affective involvement of speakers also vary along with shifts in perspective. We conceptualize this process as a mechanism used for regulating affective involvement on the part of the speakers during in-session interaction either by the speaker's selfregulation, or through interactive or interpersonal regulation. We define interpersonal regulation of the speakers by assuming that they influence each-other's perspective shifts, through a coordination of perspectives (Garrod \& Pickering, 2009; Berán \& Unoka, 2005).We make a case that this method can be used for measuring expression of affective involvement of the speakers, analyzing both self-regulative aspects and interactive aspects of regulation.

\section{Measures of In-Session Regulation of Affective Involvement}

Since various psychotherapy approaches aim to develop and improve skills for emotional functioning (Berking et al., 2008), it is important that clinical research focuses on various aspects of this process, such as experience, regulation, and awareness (Sloan \& Kring, 2007). Affect regulation - including processing, modulating and expressing emotion experience — has been traditionally measured by self-report questionnaires (Alpers, Wilhelm, \& Roth, 2005; Gross \& John, 1997; Kring, Smith, \& Neale, 1994; Watson, Clark, \& Tellegen, 1988), coding of facial emotion expressions (Kring \& Sloan, 2007), as well as online physiological measures (Alpers et al., 2005). Several methodological considerations suggest, however, that the method of audio recording and transcribing sessions could be a useful way of examining in-session affect regulation (Sloan \& Kring, 2007; Thoma \& Kachele, 2006; Wallerstein, 1988; Wallerstein, 2005; Watson et al., 2011). The argument for analyzing psychotherapy transcripts with such a goal involves problems presented by other methods. For example, in case of post-session self-report questionnaires estimations of affective intensity may not be exact, and the person responding to the Language and Psychoanalysis, 2017, 6 (2), 76-98 
questionnaire may not only be influenced by recent affective experience, but also by the knowledge of how s/he is supposed to feel in such situations (Robinson \& Clore, 2002). In the case of facial coding of emotion expression the training of coders is a long and expensive process, and in addition, video recording may interfere with the natural processes of psychotherapy (Sloan \& Kring, 2007). Another, more intrusive measure is the online measure of physiological variables, which is not widely used by clinicians, since again, it may interfere with the psychotherapy process. Audio recording of sessions is a less intrusive method of data collection, and there is no technical personnel needed to be present at the sessions. In addition, verbatim transcripts give an immediate direct insight into the events of the session as opposed to post-session self-report questionnaires.

The literature of analyzing in-session transcripts has been ever growing (Luborsky, 1977; Perakyla, Antaki, Vehvilainen, \& Leudar, 2008; Price \& Jones, 1998), but in fact only in a handful of cases was this method used for analyzing affect regulation of the speakers (Bucci, 1995; Bucci, 2001; Mergenthaler, 1996; Thoma \& Kachele, 2006). These studies have focused on psychoanalytic psychotherapies. Mergenthaler (1996) identified key moments or breakthroughs in in-session interaction by first differentiating sequences of talk rich in emotional expression, and sequences focusing on more abstract topics using content analysis. The emotion-abstraction cycles of the therapy allowed him to locate key moments of treatment. Bucci (2001) in a somewhat similar line of thought used the concept of referential activity to relate language use at the session to unconscious or conscious imagery, body and emotion experience. Thomä and Kächele (2006) in their computerized content analysis method analyzed emotionality of words and expressions distinguishing positive and negative affect related to the self or to the other.

In our study, we use a novel approach for the narrative analysis of regulating affective involvement, examining NP patterns used by the speakers. NP, as we mentioned earlier, refers to the narrator's point of view, expressing the narrator's relationship to events and characters of the narrative. NP is measured by linguistic variables, expressing affective involvement of narrators. Our method for choosing variables of NP expressing affective involvement has been based on previous experimental studies mainly from the cognitive and autobiographical memory literature.

\section{Affective Involvement Expressed in NP}

Previous studies examining structural characteristics of narratives showed that affective involvement during reading and listening to stories is related to structure as much as to content of narratives. For example, stories of severe loss (death of a close relative) result in stronger affective reaction in listeners than a less severe loss (death of a pet) (Habermas \& Diel, 2010). At the same time, experience of remembering of past events and affective involvement in narrating past experiences is also expressed in the particular wording (Barclay, 1996), and formal structural elements of narratives, such as the perspective of speaker/narrator (Berán \& Unoka, 2005; Berán \& Unoka, 2012; Habermas \& Diel, 2010; Pólya, Kis, Naszódi, \& László, 2007). Thus, evidence suggests that affective involvement of the self is expressed in various aspects of perspective: use of verb tense (Pólya et al., 2007; Schiffrin, 1981; Tannen, 1989; Wolfson, 1979), subject person and number (Gambini, Barbieri, \& Scarone, 
2004; Jackson, Meltzoff, \& Decety, 2006; McIsaac \& Eich, 2002; Sutin \& Robins, 2008), description of emotions and mental contents (Habermas, 2006; Sabatinelli, Lang, Bradley, \& Flaisch, 2006), as well as detail and specificity of description (Baumeister \& Newman, 1994; Raes, Hermans, de Decker, Eelen, \& Williams, 2003), and the episodic character of the remembered story as opposed to general or semantic knowledge (Barclay, 1996; Conway \& Pleydell-Pearce, 2000; Conway, 2009).

The varied use of verb tense has been related to expression of affect intensity in personal narratives (Pólya et al., 2007; Wolfson, 1979). Shifting to present tense while narrating past events dramatizes expression, making it more vivid (Schiffrin, 1981; Tannen, 1989), resulting in an impression of increased emotional intensity and involvement (Pillemer, Desrochers, \& Ebanks, 1998; Pólya et al., 2007), as well as honesty perceived by listeners (Habermas \& Diel, 2010). In addition, in narrative terms the self is experienced as a flow of consciousness making sense of the world moment by moment in the actual present time, and hence we considered the verbal use of present tense to be closer to this actual self-experience. Therefore, in our model of NP variables we use verb tense to assess affective involvement of the self. Using present tense is treated as signaling more intense emotional involvement in comparison to past tense verbs, or the very rarely used future tense (Berán et al., 2011).

A deeper involvement is suggested when the narrator is part of the story world he/she is describing, compared to when he/she is recounting events from an outsider's point of view (Kenny et al., 2009; Sutin \& Robins, 2008). The narrator's talking in first person singular in contrast to third person has also been shown to express greater selfinvolvement (Gambini et al., 2004; Jackson et al., 2006; McIsaac \& Eich, 2002; Rice \& Rubin, 2009; Sutin \& Robins, 2008). We use three variables to express subjective position of the narrator in order to capture the above mentioned aspects: inside or outside narrator position (diegesis variable), and subject number and person variables. We consider first person singular subject and inside narrator position to express more intense affective involvement of the speaker.

A more intense emotional expression and involvement characterize narrators when they include mental state descriptions such as affective states, emotions, feelings, intentions, desires, thoughts (Habermas, 2006; Sabatinelli et al., 2006) - as opposed to describing events and behaviors without reference to mental states. Description of mental states may include the narrator's own mental states or mental states of other characters in the narrative manifesting what has been referred to as intentional stance (Dennett, 1989), theory of mind (Fletcher et al., 1995), or a mentalizing attitude (Fonagy, 2006) towards self and/or others. In our model we used the variable "focalization" to capture this aspect of NP. In focalization we distinguished a) internal focalization: where the narrator included reference to mental states of self and/or others, and b) external focalization when he/she did not refer to mental states, only giving information on events and overt behavior of self and/or characters in a given unit of analysis. Internal focalization is considered to be more affectively rich than external focalization.

Narrating a concrete, specific life episode in more detail as opposed to talking about general life experience, or summarizing over lengthy time periods of the life story suggests deeper self-involvement of the narrator (Baumeister \& Newman, 1994; Raes

Language and Psychoanalysis, 2017, 6 (2), 76-98

http://dx.doi.org/10.7565/landp.v6i2.1573 
et al., 2003). Giving a more detailed description of events expresses more intense involvement than vague statements and lack of detail (Bucci, 2001; Conway, 2009). According to Barclay (1996) emotional intensity characterizing episodic memories can be traced in verbal expressions of emotion, greater cohesion of memory, shorter expansion of time period described by the memory, presence of spatial temporal contextual information, and causal expressions, richer perceptual detail. In our conceptualization of NP we used the discourse level variable to capture these distinctions. This variable differentiates three positions of the person narrating the story: 1. discourse position, referring to the here and now of the therapeutic situation, 2. narrator position, referring to the taking of the position of the narrator of the story, 3. character position, referring to the taking the position of a character in the story: the narrator's formal self, or another character. These three positions differ in terms of subjective knowledge, and affective involvement. The first level differentiates the narrative from other discourse activities at the session referring to the here-and-now of the actual situation. The narrator and character positions differ in terms of autobiographic memory type: in the former position the speaker recounts memories that are more general, refer to longer periods of the life story, whereas the character position refers to unique episodes (Conway, 2009). This latter position requires more intense affective involvement of the self.

\section{Affect Regulation During Joint Construction of Narratives}

Construction, reconstruction and transformation of the client's self-narratives is part of the therapeutic process in various types of psychotherapies, including psychoanalysis (Angus \& McLeod, 2004). The therapist's interventions and other contributions (e.g. listening clues to the client) are also part of this process. Thus, we can talk of the joint construction of narratives by client and therapist in the therapy session, emphasizing this interactive facet of treatment, and the fact that the newly reconstructed and transformed narratives of the client are partially attributed to the therapist's contributions. In the joint construction of narratives during psychotherapy, we describe two types of affect regulation processes: self-regulation, and interpersonal regulation, both detectable in shifting of NP.

The first kind, self-regulation is expressed in continuous talk of each participant, when shifting from one NP to the next. The second type, interpersonal regulation, is expressed in the segment of talk of one participant following the other speaker, for instance the client following the therapist's intonation unit, and shifting to the perspective of the previous speaker. In this case, the shift in perspective is attributed to the coordination of perspectives between the speakers (Berán \& Unoka, 2012). The cognitive background of the interpersonal regulation process is similar to the coordination and alignment of other discourse phenomena, such as bodily posture, grammatical structures, choice of wording (Garrod \& Pickering, 2009). In the joint attention situation at the session, the speakers direct each-others attention to certain aspects of the narrative (Berán \& Unoka, 2005; Chafe, 1994; MacWhinney, 2005; Nelson \& Fivush, 2004). The directing of attention is realized while the speaker's and listener's attention is jointly focused at telling of and listening to the narrative.

In our study, we suggest that both self and interpersonal regulation has a role in regulating affective involvement of the self. We examine long-term changes in affect

Language and Psychoanalysis, 2017, 6 (2), 76-98

http://dx.doi.org/10.7565/landp.v6i2.1573 
regulation of one client-therapist dyad by comparing use of NP patterns of the speakers from the initial and working phases of therapy. Specifically we hypothesize that expression of affective involvement will be more intensive over time, so that both the therapist's and the client's expression will be more affect intensive by the working phase of therapy compared to the beginning phase. We hypothesize that this will be detectable overall and by the individual variables measured. The increase of affective involvement is a sign that the participants have developed trust and emotional attachment towards each other, which makes it possible to tell stories that reflect deeper involvement, which is related to alliance as well (Levy et al., 2006). We also hypothesize that the client's affective involvement will be more intense than the therapist's, due to the differing roles they play in therapeutic discourse: the client telling his own stories showing higher affective involvement, whereas the therapist trying to keep affective involvement at an optimal level for the purposes of therapeutic work. Hence, we expect that the therapist typically down-regulates affect, whereas the client up-regulates. Assessing self and interactive regulation of the participants we also describe the affect regulation cycle characterizing the session.

\section{Methods}

\section{Data Collection and Sampling}

The data for the current study has been collected between 2004 and 2006 as part of the Budapest Psychotherapy Data-base by two of the authors, in Budapest, Hungary, in Hungarian language. 15 audio-recorded sessions of long term psychoanalytic therapeutic treatment were recorded with the given client-therapist dyad for a period of 18 months into treatment from the onset of therapy. Sessions were recorded during three time periods: five consecutive sessions at the beginning phase of treatment, five consecutive sessions in the middle of the observation period (working phase of therapy) and five consecutive sessions at the end of the observation period (working phase of therapy). The current study uses the recorded text of two 50 minutes long therapy sessions with a male therapist - male client dyad. One session examined here is randomly selected from the beginning phase of psychotherapy, a few months after its onset (referred to as early session). We compare this session, which we consider the base-line, with another session randomly selected from the working phase of therapy, after 1.5 years (referred to as the late session).

\section{Participants}

Participants were volunteers, and received no compensation for participating in the study. The therapist participating in the study is a trained and licensed clinical psychologist and psychoanalyst in Budapest, Hungary. $\mathrm{He}$ is a member of the Hungarian Psychoanalytic Association and the International Psychoanalytic Association. The treatment method applied was psychoanalysis, more specifically object relation theory. Treatment was applied three or four times a week. The client in the study is a middle aged (41 yrs) high level professional, unemployed at the time, previously working in state bureaucracy. He lived in Budapest, Hungary at the time of his treatment. His family background is middle class, he had a university degree, and was single at the time. His diagnosis assessed by his analyst indicated on DSM-IV-R included Axis I: Dysthymia, and Panic disorder, Axis II: Obsessive, Paranoid Personality disorder with Narcissistic traits. He had no axis III disorders, and on Axis 
IV: mild stress. His medical history included suicide attempts; on one occasion he needed medical help because of his suicide, and he had been previously admitted to inpatient psychiatric treatment.

\section{Ethical Considerations}

The study was approved by the board of Semmelweis University Regional and Institutional Committee of Science and Research Ethics, Budapest. Participants have signed the informed consent form in which they agreed to the anonymous use of their material for scientific and educational purposes. Also, participants had the chance to resign at any point of the observation period, if they felt uncomfortable. Since recordings were carried out by the therapist, the researchers did not meet the client personally. In order to preserve privacy of the client and therapist by keeping their identity anonymous we deleted all personal information from the text-files, such as names of persons and places, dates of events, and replaced by fictive names and dates, etc.

\section{Data Transcription}

As described in Berán and Unoka (2015): Audio-recorded therapy sessions were transcribed by the first author using the transcription codes of the Child Language Data Exchange System (MacWhinney \& Snow, 1990). Talk at the session was transcribed verbatim, segmenting the speech flow into intonation units, as defined by Chafe (1994) in English, and by Németh (1996) in Hungarian. According to this, an intonation unit was defined as a group of words bounded by silence, a short pause or final intonation contour to signal question, period, or exclamation. Single words, sentence fragments could also be considered separate or fragmented intonation units. One typical 50 minutes session consists of about 1000 intonation units.

\section{Coding of NP}

Coding of NP was based on the original transcript in Hungarian, according to the system described in the Handbook of Coding Narrative Perspective (Berán, 2009). We used the following variables in coding NP for each individual intonation unit line:

1. Verb tense: the grammatical verb tense in Hungarian includes three categories: past (1), present (2), and future (3), signaled in the verb suffix. In case there was no verb in the given intonation unit, or syntactically related clause, we coded non-applicable (0).

2. The narrator/character's relation to the story world (i.e., "diegesis"), where narrated events take place. The narrator him or herself may be part of the story world, by participating in events of the story: inside-narrator or homodiegesis, (1), or may not be participating in it, rather looking at it from the outside: outside-narrator or hetero-diegesis (2). For example, in the following dialogue between the client $(\mathrm{C})$ and therapist $(\mathrm{T})$, the client uses the inside narrator position, whereas the therapist uses the outside position:

$\mathrm{C}$ : for example, when last time we talked about this, about the children and everything, my brain like like it did not stop about it when I left here.

$\mathrm{T}$ : and what came to your mind?

Language and Psychoanalysis, 2017, 6 (2), 76-98 
The third (rather rarely used) category is the so called pseudo-narrator position or pseudo-diegesis (3), when the narrator identifies with a character of the story, and shifts to their point of view. This is accomplished usually with direct quotation. For example, in the following monologue of the client we find a shift from hetero to pseudo-diegesis. The client is talking about difficulties of raising children: "That they can take it lightly. You know 'cause 'they are fine, no need to worry about them', I don't know." Here the 'they are fine, no need to worry about them' is a direct quotation of those kind of parents' thinking or speaking who take it lightly. The client illustrates his argument by directly expressing their point of view. In case the diegesis variable could not be applied to a given intonation unit (for instance due to fragmentation of the unit), we used the non-applicable (0) category.

3. Grammatical subject: number. This is the same in Hungarian as in English, except that in Hungarian the subject number may also be placed in the verb suffix. The subject could be singular (1) or plural (2). In case there was no subject in a given intonation unit or syntactically related clause, we used the non-applicable category (0). For example, in the following quote from the client: "not only that I have never experienced, but I have not ever heard such a thing from anybody" is a singular subject.

4. Grammatical subject: person. This is the same in Hungarian and in English. The subject could be first (1), second (2), or third (3) person. We also distinguished impersonal (general) subject (4), or used the non-applicable category if there was no subject present in a given intonation unit or syntactically related clause (0). For instance, using the above example: "not only that I have never experienced, but I have not ever heard such a thing from anybody", we coded first person, because the subject was the ' $I$ '.

5. Mode of focalization: The narrator's way of perceiving his/her own, and other character's inner world, his/her knowledge or lock of knowledge of it. Describing feelings, thoughts, desires or just overt behavior. We differentiated intonation units which only describe overt behavior and events, called external mode of focalization (1), from those expressing mental contents (emotions, desires, intentions, etc.), called internal mode of focalization (2). Also, we used the non-applicable category $(0)$ if focalization could not be interpreted on a given intonation unit or syntactically related clause (for instance, in case of fragmented intonation units).

6. Discourse level: Positions the narrator in terms of whether he/she is telling the story in the here and now of the therapeutic session, talking about the thoughts and feelings related to what is happening in the present: 'here and now of the therapeutic session' (1); or recalling general autobiographical information referring to repeated, or typical events, or extended life-time periods (Conway, \& Pleydell-Pearce, 2000): 'narrator's level' (2); or recalling autobiographical information related to a specific episode, a one-time event in the speaker's past life: 'character's level' (3). We used the non-applicable (0) category when discourse level could not be determined, for example, in case of fragmented intonation units. Let us look at the following dialogue, in which the client is talking about his humiliation at his former workplace:

C: well and after that it followed that when they handed out rewards, which of course you know that it's called a reward in the administration, but it is like everyone gets that.

Language and Psychoanalysis, 2017, 6 (2), 76-98 
T:Yes.

$\mathrm{C}$ : so it is practically an extension of your sellary. And then what happened was that everyone got it, but me. And this was even especially emphasized at the meeting, like because $S$. does not get it.

At the beginning of the dialogue the client is talking about general information related to autobiographical events that repeatedly and typically occurred during the period he was working at the given institute. Therefore intonation units here were coded as narrator's level. From the point of "And then what happened..." he shifts into a concrete life-episode describing how he was mistreated and then humiliated at the meeting at one time. Therefore, intonation units in this section were coded as character's level. The level of the "therapeutic here-and-now" often takes the form of the therapist's interpretations or interventions. Let us look at the following dialogue:

$\mathrm{T}$ : so we may even think that that has been an ideal situation, because there was no female boss.

$\mathrm{C}$ : that's right.

Intonation units of the dialogue were coded as therapeutic-here-and-now, because it refers to the current situation, what we may think of previous events now, in retrospect.

Coding for the two sessions was carried out by the first author, inter-rater reliability was computed based on 300 intonation units of the total transcript coded by two independent raters. Cohen's kappa was 0.63 , which shows a substantial level of agreement.

\section{Measures of Affective Involvement and Affect Regulation}

To measure affective involvement of the self expressed in talk we created a 7 point scale using the following variable values: inside narrator, present tense, first person, singular, character level, internal focalization - each representing one point on the "affective involvement of the self" scale. We computed values for each intonation unit for affective involvement. Regarding affect levels we distinguished sequences based intonation units (self vs. interactive regulation), testing regulative role of NP accomplished by shifting. We distinguished four types of intonation units, based on intonation unit sequences, always analyzing the first unit after the change of speaker:

1) Intonation unit produced by the client was followed by another intonation unit also produced by the client ( $\mathrm{CC}$ unit);

2) Intonation unit produced by the therapist preceded by client's intonation unit (CT unit), analyzing units ' $\mathrm{T}$ ';

3) Intonation unit produced by therapist followed by another also produced by the therapist (TT unit);

4) Intonation unit produced by the client preceded by the therapist's intonation unit (TC unit), analyzing units ' $\mathrm{C}$ '. We also computed level of affective involvement for each sequence based unit, using the same method as described above. 


\section{Statistical Analysis}

For statistical analysis we used the Statistical Analysis System (SAS) 9.4 package. In the statistical analysis of sequence based units we found that much of the therapist's contribution consisted in giving listening clues to the client, in other words short feedback ensuring the client that the therapist is there, paying attention to what he

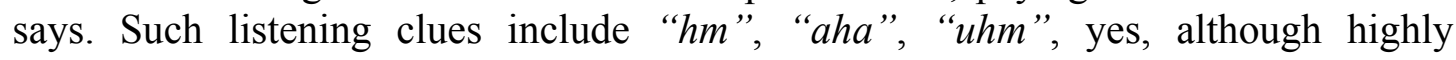
important in therapy, however, could not be coded in terms of expressing a specific NP. Therefore they were coded as Not-Applicable (NA). This category also included intonation unit fragments that would stand outside of contextual meaning, not expressing any interpretable perspective.

In our analysis we created cross-tabulations in order to investigate the distribution of variable categories. Due to large number of intonation units, in the categories we typically had a high number of cases. We used Generalized Linear Integrated Mixed Model analysis (GLIMMIX procedure, SAS 9.4 version) to identify significant differences in distributions according to categories. This model allows for handling repeated measures and clustered, dependent data (Liang, \& Zeger, 1986; Lin, \& Breslow, 1996), such as those observed between the therapist and client across the repeated intonation units. Furthermore, it makes possible to investigate variables that deviate from Gaussian distribution, including polychotomous categorical data that are measured at a nominal scale (Koch, Carr, Amara, Stokes, \& Uryniak, 1990) (e.g., verb tense, diegesis, subject number, focalization, person, discourse level). Categorical variables measured at a nominal scale were tested in our study using the multinomial distribution with the generalized logit function; ordered categorical data (such as level of affective involvement), were tested using the multinomial distribution with the cumulative logit function.

\section{Results}

\section{Descriptive Statistics}

In order to examine distribution of speech among client and therapist, we assessed distribution of intonation units between client and therapist as shown in Table 1. Data suggest that the client talked about four times as much as the therapist at both sessions.

Table 1

Distribution of intonation units by speaker and session

\begin{tabular}{ccc}
\hline Who speaks? & Frequency & Percent \\
\hline Early session & & \\
Client & 740 & 80.2 \\
Therapist & 183 & 19.8 \\
Late session & & \\
Client & 1113 & 88.3 \\
Therapist & 147 & 11.7 \\
\hline
\end{tabular}




\section{Testing of Hypotheses}

According to our hypothesis, we expect affective involvement to increase by the late session. In order to test whether there was a difference in affective involvement at the sessions we used our seven point scale described above measuring affective involvement of the speakers and used the Generalized Linear Integrated Mixed Model analysis (GLIMMIX) to determine the difference of involvement at the early and late sessions by speaker. This model allows for handling repeated measures data, and variables that deviate from Gaussian distribution. There was a main effect for session, $\mathrm{F}(3,2183)=39.23, \mathrm{p}<0.0001$, with mean values $(\mathrm{M})$ indicating that affective involvement was higher at the late session (for the early session $\mathrm{M}=2.97, \mathrm{SD}=1.29$; for the late session $\mathrm{M}=3.30, \mathrm{SD}=1.11$ ), thus confirming our hypothesis. In order to test whether the client's involvement was higher than the therapist's - as we stated in our hypothesis - we also compared affective involvement between client and therapist. There was a main effect for speaker, $\mathrm{F}(3,2183)=81.65, \mathrm{p}<0.0001$, with mean values indicating that the client's affective involvement was higher than the therapist's (for the client $\mathrm{M}=3.19, \mathrm{SD}=1.19$; for the therapist $\mathrm{M}=2.48, \mathrm{SD}=1.20$. There was no interaction between speaker and session, $\mathrm{F}(3,2183)=0.04, \mathrm{p}=0.83$ (for the early session, for the client $\mathrm{M}=2.92, \mathrm{SD}=1.29$, for the therapist $\mathrm{M}=2.29$, $\mathrm{SD}=1.17$; for the late session for the client $\mathrm{M}=3.37, \mathrm{SD}=1.08$, for the therapist $\mathrm{M}$ $=2.72, \mathrm{SD}=19$ ).

In order to examine distribution of NP variables among speakers at the two sessions, we performed a GLIMMIX analysis between the categories of each NP variable in order to test whether there was an association between session type (early and late) and NP patterns for each speaker. Table 2 shows the distribution of the six NP variables according to speaker by session as well as GLIMMIX test results for comparisons of early and late sessions. 
c. Verbe Tense

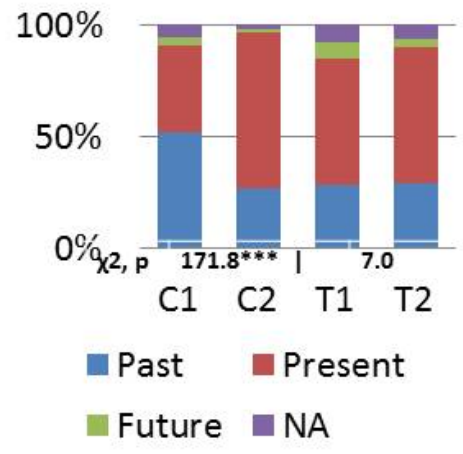

d. Diegesis

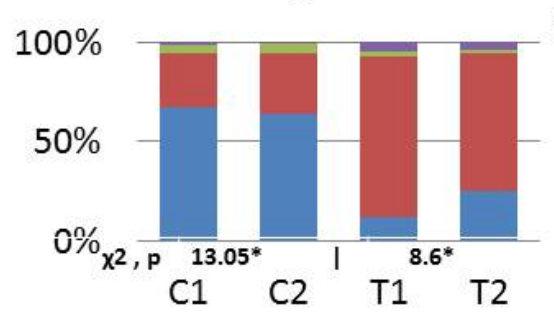

NA

Pseudo-Narrator

- Outside-Narrator

- Inside-Narrator b. Subject number

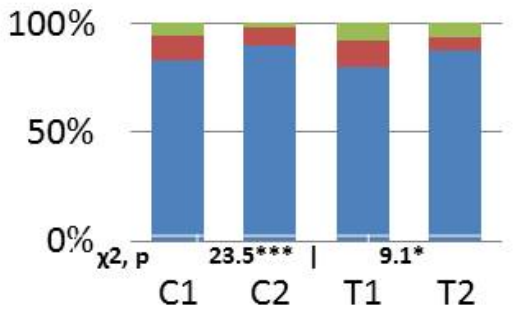

- Singular $=$ Plural $=\mathrm{Na}$

e. Focalisation a. Person

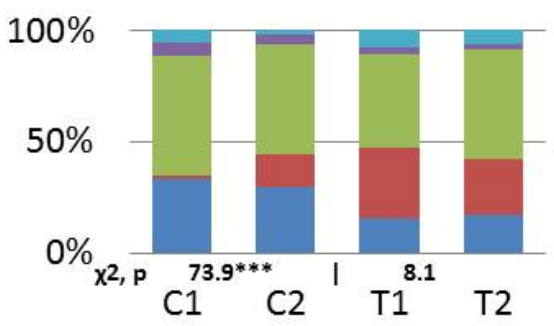

airst $\quad$ Second $\square$ Third

a General $\square \mathrm{Na}$

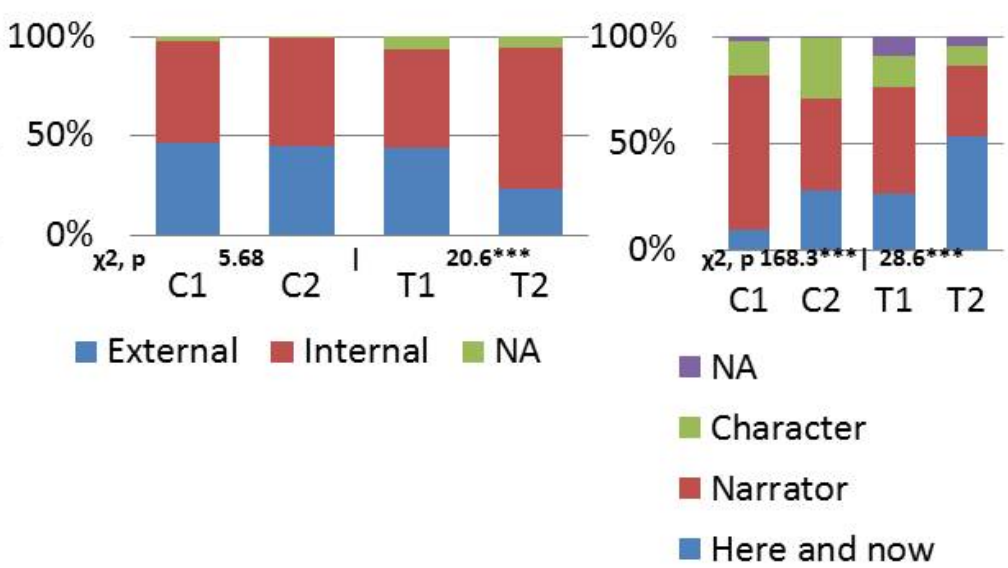

\section{Figure 1}

Distribution of the six NP variables in intonation units by speaker and session

Note. $\mathrm{C} 1=$ the client's intonation units at the early session; $\mathrm{C} 2=$ the client's intonation units at the late session; $\mathrm{T} 1=$ the therapist's intonation units at the early session; $\mathrm{T} 2=$ the therapist's intonation units at the late session; NA $=$ non-applicable. ${ }^{*} \mathrm{p}<0.05, * * \mathrm{p}<0.01, * * * \mathrm{p}<0.0001$

Results of GLIMMIX tests show that in the client's talk there was a significant difference between NP patterns used at the early and late sessions in case of four variables: verb tense, subject number and person, and discourse level. Thus, in case of these variables, there was a relationship between early and late session and distribution patterns. In the therapist's talk, the variables of diegesis, focalization, discourse level, and subject number showed significantly different patterns of distribution between sessions.

We used sequence-based intonation units to measure potential effects of affect regulation of the speakers. For this, we used the four types of sequence-based units described above. In total, there were $1577 \mathrm{CC}$ units (589 at the early, and 988 at the late session), $276 \mathrm{CT}$ units (152 at the early, and 124 at the late session), 277 TC units (151 at the early, and 126 at the late session), and 172 TT units (110 at the early, and 62 at the late session). 
In order to understand distribution of sequence based intonation units, we used again a GLIMMIX analysis. Figure 2 shows the distribution of the six variables of NP for the four types of sequence based intonation units by session. We tested if there was a difference in NP distribution patterns among the sequence based unit types at a given session. We found a significant difference among sequence based unit types both at the early, and at the late sessions, except for focalization at the early, and verb tense at the late session, which were not significant.

\section{Verb tense}
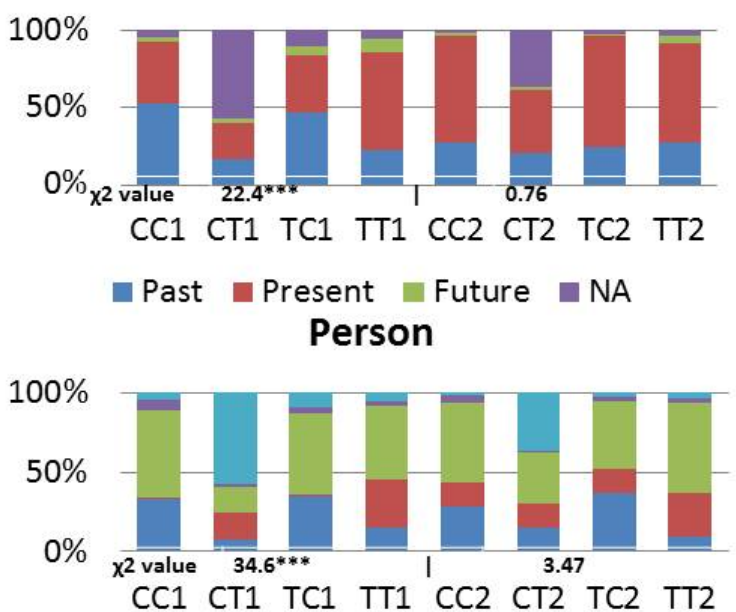

E First $\square$ Second $\square$ Third $\square$ General $\square$ NA Focalization

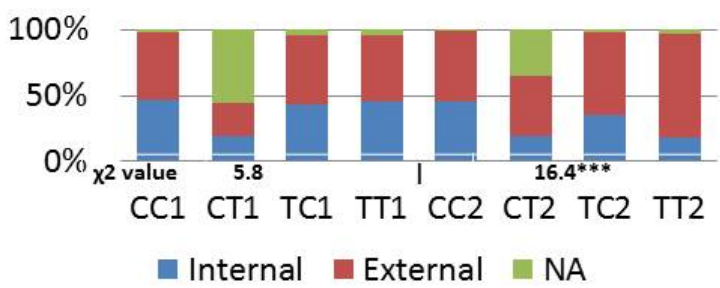

Subject number

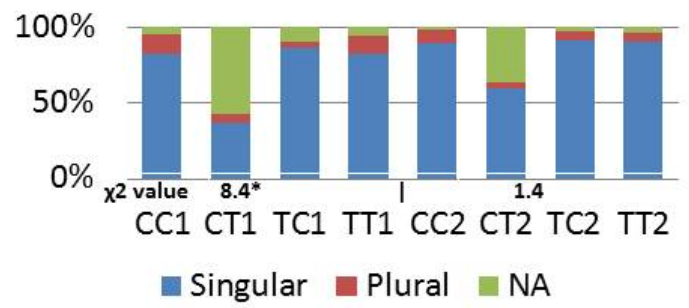

Diegesis
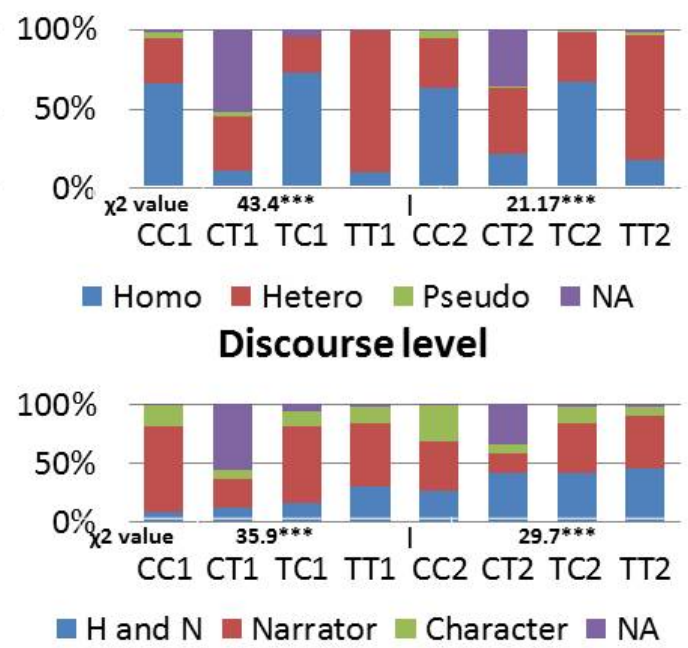

\section{Figure 2}

Distribution of the six NP variables for sequence-based intonation unit by session

Note. $\mathrm{CC}=$ sequence based unit where the client's intonation unit is preceded by another of the client's intonation unit; CT $=$ sequence based intonation unit where the therapist's unit is preceded by the client's unit; TC = sequence based unit where the client's unit is preceded by the therapist's intonation unit; TT = sequence based intonation unit, where the therapist's unit is preceded by another of the therapist's unit; $\mathrm{C} 1=$ the client's intonation units at the early session; $\mathrm{C} 2=$ the client's intonation units at the late session; $\mathrm{T} 1=$ the therapist's intonation units at the early session; $\mathrm{T} 2=$ the therapist's intonation units at the late session; NA $=$ non-applicable. $* * * p<.0001$

To test the difference in affective involvement based on our seven point scale between sequence based unit types in total, we used the GLIMMIX procedure since this variable (total) represents ordinal-scale measure. We characterized self regulation of 
the speakers by $\mathrm{CC}$ and TT unit types, and interactive regulation by CT (interactive effect of the client on the therapist's speech) and TC (interactive regulation effect of the therapist on the client) unit types. There was a significant difference among sequence based unit types overall $F(7,20301)=148.86, p<0.0001$. Table 2 shows the significance of differences among unit types. CC and TC type units showed the most affective involvement, and there was no significant difference between them (for $\mathrm{CC}$ units $\mathrm{M}=3.18, \mathrm{SD}=1.17$; for $\mathrm{TC}$ units $\mathrm{M}=3.20, \mathrm{SD}=1.3$ ). $\mathrm{TT}$ units showed the next highest level of involvement $(\mathrm{M}=2.48, \mathrm{SD}=1.05)$, and $\mathrm{CT}$ type units showed the lowest $(\mathrm{M}=1.47, \mathrm{SD}=1.58)$.

\section{Table 2}

Significance of differences in affective involvement ${ }^{\mathrm{a}}$ among types of sequence based intonation units over the two sessions

\begin{tabular}{llll}
\hline & $\mathrm{CC}$ & $\mathrm{CT}$ & $\mathrm{TC}$ \\
\hline $\mathrm{CC}$ & & & \\
$\mathrm{CT}$ & $<.0001^{\mathrm{C}}$ & & \\
$\mathrm{TC}$ & $0.2412^{\mathrm{C}}$ & $<.0001^{\mathrm{R}}$ & \\
$\mathrm{TT}$ & $<.0001^{\mathrm{C}}$ & $<.0001^{\mathrm{R}}$ & $<.0001^{\mathrm{C}}$ \\
\hline
\end{tabular}

Note. ${ }^{\text {a }}$ : affective involvement was measured on a 7-point scale

$\mathrm{CC}=$ sequence based unit where the client's intonation unit is preceded by another of the client's intonation unit; $\mathrm{CT}=$ sequence based intonation unit where the therapist's unit is preceded by the client's unit; TC = sequence based unit where the client's unit is preceded by the therapist's intonation unit; TT = sequence based intonation unit, where the therapist's unit is preceded by another of the therapist's unit; index letters $\mathrm{C}$ and $\mathrm{R}$ indicate whether the column or row sequence-based unit showed higher level of affective involvement, respectively.

Table 3 shows that this same pattern was the case for both sessions: for the early session, the Mean for CC units was $2.90(S D=1.28)$, for TC it was $2.98(S D=1.32)$, for TT it was $2.35(S D=1.08)$, and for CT it was $1.11(S D=1.40)$. For the late session the Mean for CC units was $3.35(S D=1.06)$, for TC it was $3.46(S D=1.23)$, for TT it was $2.69(S D=0.96)$, and for CT it was $1.90(S D=1.68)$. 


\section{Table 3}

Significance levels for differences in affective involvement ${ }^{\mathrm{a}}$ among types of sequence based units by session

\begin{tabular}{llccccccc}
\hline & \multicolumn{9}{c}{ Early session } & \multicolumn{3}{c}{ Late session } \\
\hline Early & $\mathrm{CC}$ & \multicolumn{1}{c}{$\mathrm{CC}$} & $\mathrm{CT}$ & $\mathrm{TC}$ & $\mathrm{TT}$ & $\mathrm{CC}$ & $\mathrm{CT}$ & $\mathrm{TC}$ \\
session & $\mathrm{CT}$ & $<.0001^{\mathrm{C}}$ & & & & & & \\
& $\mathrm{TC}$ & 0.4491 & $<.0001^{\mathrm{R}}$ & & & & & \\
& $\mathrm{TT}$ & $<.0001^{\mathrm{C}}$ & $<.0001^{\mathrm{R}}$ & $<.0001^{\mathrm{C}}$ & & & & \\
Late & $\mathrm{CC}$ & $<.0001^{\mathrm{R}}$ & $<.0001$ & $0.0004^{\mathrm{R}}$ & $<.0001^{\mathrm{R}}$ & & & \\
session & & & $\mathrm{R}$ & & & & & \\
& $\mathrm{CT}$ & $<.0001^{\mathrm{C}}$ & $<.0001^{\mathrm{R}}$ & $<.0001^{\mathrm{C}}$ & 0.0045 & $<.0001^{\mathrm{C}}$ & & \\
& $\mathrm{TC}$ & $<.0001^{\mathrm{R}}$ & $<.0001^{\mathrm{R}}$ & $<.0010^{\mathrm{R}}$ & $<.0001^{\mathrm{R}}$ & 0.3690 & $<.0001^{\mathrm{R}}$ & \\
& $\mathrm{TT}$ & 0.2101 & $<.0001^{\mathrm{R}}$ & 0.1171 & 0.0783 & $<.0001^{\mathrm{C}}$ & $<.0001^{\mathrm{R}}$ & $<.0001^{\mathrm{C}}$ \\
\hline
\end{tabular}

Note. ${ }^{\text {a}}$ : affective involvement was measured on a 7-point scale

$\mathrm{CC}=$ sequence based unit where the client's intonation unit is preceded by another of the client's intonation unit; CT $=$ sequence based intonation unit where the therapist's unit is preceded by the client's unit; TC = sequence based unit where the client's unit is preceded by the therapist's intonation unit; TT = sequence based intonation unit, where the therapist's unit is preceded by another of the therapist's unit; index letters $\mathrm{C}$ and $\mathrm{R}$ indicate whether the column or row sequence-based unit showed higher level of affective involvement, respectively.

We also calculated LS means and standard errors for sequence based unit types by session. At the early session LS mean for CC units was $2.90(\mathrm{SE}=0.05)$, for TC it was $2.98(\mathrm{SE}=0.10)$, for $\mathrm{TT}$ it was $2.35(\mathrm{SE}=0.12)$, and for $\mathrm{CT}$ it was $1.11(\mathrm{SE}=$ $0.10)$. For the late session LS mean for $\mathrm{CC}$ unit was $3.36(\mathrm{SE}=0.04)$, for TC it was $3.46(\mathrm{SE}=0.11)$, for TT it was $2.69(\mathrm{SE}=0.15)$, and for $\mathrm{CT}$ it was $1.9(\mathrm{SE}=0.11)$.

\section{Discussion}

The goal of our study was to introduce a novel method for studying regulation of affective involvement in psychoanalytical psychotherapy, and show its usefulness of application by examining regulation of affective involvement in two psychoanalytic sessions taking place 1.5 years apart. We defined affect regulation as the capability to process, modulate, and express affective experience (Watson et al., 2011) and we argued that studying verbatim transcripts of therapeutic sessions allows for identification of narrative structures that have different levels of affective involvement; shifting between these levels reflects a regulation of affective involvement. Our study provides evidence that this approach to examining in-session affective involvement can be useful for understanding self - and interactive aspects of affect regulation. Our results show in general the support of our main hypotheses regarding differences of affective involvement between the sessions, as well as the speakers. 
Based on the number of intonation units uttered by speakers we found that the client used four times more intonation units than the therapist. Since this pattern was similar at both sessions, in the case of this client-analyst dyad we found this pattern fitting into the popular image of psychoanalytic discourse where the client does much of the talking, and the therapist's role requires him/her mainly to listen.

Affective involvement for both speakers was higher at the late session, after the client has been in analysis for 18 months. This supports our hypothesis that after being in therapy for a substantial period of time, telling of stories that express higher affective involvement becomes possible for the client, since this requires trust and emotional attachment between the participants (Levy et al., 2006). In addition, in certain type of therapies (e.g. experiential treatment) deeper emotional processing - defined as an integration of cognitive and affective aspects of emotion experience - is viewed as the most important therapeutic task, goal, and part of the change process (Greenberg \& Pascual-Leone, 1995; Missirlian, Toukmanian, Warwar, \& Greenberg, 2005; Watson \& Greenberg, 1996; Watson, Greenberg, \& Lietaer, 1998). In line with this, Pos, Greenberg, Goldman and Corman (2003) demonstrated that emotional processing independently predicted improvement in case of depressed clients in brief experiential therapy.

In psychoanalytic therapy Freud (1926/1959) emphasized that regulation of anxiety and in general negative affect arising from conflicts between the ego and reality, as well as from conflicts between the ego and super-ego or the id was an important part of the therapeutic process. According to Mergenthaler's therapeutic cycles model of psychoanalytic therapy $(1996,2004)$ there are phases of treatment (or session) that show increased affect levels, and its function in the analysis is emotional experiencing on the client's part. Thus, it may be the case that increase of affective involvement on the client's part contributes to improved emotional experiencing and processing in psychoanalytic therapy as well.

Our finding that the mean levels of affective involvement in the client's intonation units were higher at both sessions than the analyst's, further emphasizes the importance of in depth emotional processing on the client's part. It also suggests that in our case, client's and therapist's roles differ in terms of affect regulating strategies in the session, as we discuss it below when describing the affect regulation cycle characteristic of the examined sessions.

Our statistical analysis showed that change of affective involvement over time in case of both speakers displayed a similar overall pattern. We suggest that this overall change may show a coordination of affective involvement between the speakers; in other words, it may be the result of interpersonal regulation. At the same time, coordination of change in affective involvement-level of the speakers may also be informative about the alliance (Gaston, 1990) between client and analyst. In order to show coordination of affective involvement they must pay close attention to eachother's level of involvement (i.e. have a high affective attunement), which may be a sign of good alliance. Along a similar line Owens, Haddock and Berry (2012) found good alliance to be associated with better emotion regulation in patients with psychosis. Furthermore, Cloitre, Stovall-McClough, Miranda and Chemtob (2004) 
found that good alliance predicting positive outcome in PTSD patients with childhood abuse was mediated by an improved capacity to regulate negative affect states.

Examining the six variables of the affective involvement scale, we found significant differences of NP patterns used by both speakers at the two sessions. The client's use of verb tense, subject number and person, and discourse level differed at the early and late sessions. Looking at verb tense, the overwhelming proportion of past tense the client used at the early session shifted to an overwhelming present tense use by the late session. Since our coding system did not differentiate between the use of present and historical present (recounting a past event in the present tense), this result may suggest that the client recounted life episodes using present tense, which represents a more intense affective involvement of the self into the narrative (Schiffrin, 1981; Pillemer, Desrochers, \& Ebanks, 1998; Pólya, Kis, Naszódi, \& László, 2007), or that he was using more present tense in his in session discussions with the therapist.

Changes in other variables also show an increase of affective involvement. The discourse level variable shows that use of character position (signaling episodic memories) has doubled by the late session in case of the client, whereas the use of narrator level (signaling memories of repeated events or extended life-time periods) which dominated the early session, decreased by half by the late session. These findings are interpreted as more intense affective involvement. At the same time this could be the sign of trust on the part of the client, since he is able to disclose emotionally richer material (episodic memory) to his therapist.

In the subject number and person variables we expected an increase of first person and singular for the late session in the client's talk. However, our results suggest that there was an increase of singular and second person proportion for the late session instead. This result suggests a more intense interaction orientation of the client, directly talking to the analyst. In addition, in the discourse level variable, the proportion of therapeutic here-and-now tripled by the late session, suggesting increased interactivity referring to the therapeutic situation. Thus, both affective involvement and more intense interaction played a role in changes in the client's talk by the late session, which again, may be related to alliance.

In the analyst's talk the use of diegesis, focalization, discourse level, and subject number variables changed from the early to the late session. These changes suggest a more intense self involvement on the therapist's part. The analyst took the inside narrator position twice as often, and used the outside narrator position less often at the late session. These changes suggest that being part of the client's story world was one way the therapist expressed his involvement in the late session. We also found that the therapist used substantially (about 20\%) more internal focalization, talking of mental content: emotions, intentions, and less frequently used merely behavioral descriptions at the late session. This also suggests more intense affective involvement by the late session. Looking at the discourse level variable, we expected the analyst to use more character position at the late session, expressing his involvement in the client's narratives. However, he used half as much character position at the late session than at the early one. At the same time, he used almost twice as much the level of here-and now of the session, as well as using more singular subjects. These results are similar to what we find at the client, and we also interpret it as a sign of increased 
relationship orientation by the late session. The increased relationship orientation on the part of both participants may also signal better alliance (Luborsky, 1976).

Looking at sequence type based units, in our analysis overall there was a difference among sequence type based units in terms of affective involvement. $\mathrm{CC}$ and TC units had the highest affect level followed by TT units, and CT had the lowest level of affect. There was no statistical interaction between session and sequence type based units, meaning that within the two individual sessions we had the same ordering of sequence type based units in terms of affect levels. An "ideal" sequence of affect regulation can be described as follows: Reacting to the client's affect-intense talk (CC) the therapist typically uses lower level affect (CT), down-regulating affective intensity. Continuously talking (TT), the therapist expresses medium-level affect, somewhat higher compared to CT, which could be called a balanced level of affective involvement. The client, reacting to the therapist's talk in TC, again uses higher levels of affect. Thus, typically, the client up-regulates, while the therapist down-regulates in interpersonal regulation, and keeps a balanced level in self regulation. This affect regulation cycle suggests that the therapist's interventions had no overall significant down-regulating effect on the client's talk, since CC and TC units showed no significant difference in affective involvement of the client, despite the therapist's down-regulating activity.

However, we must note, that in the case of individual variables both speakers may diverse from the typical regulative strategy, thus, in some cases the therapist may upregulate, and the client may down-regulate affective involvement - for example, in case of the focalization variable at the late session. Another important finding about sequence based units was that in case of four of the six variables all units differed from each other in terms of affective involvement, showing that they played a differing function in affect regulation.

\section{Limitations of the Study and Future Directions}

Our study consists of the analysis of the talk of one client-therapist dyad in psychoanalytic psychotherapy, using two sessions, which could be considered a quantitative case-study. Therefore, our results may not be generalizable to other cases, for example, to clients and therapists with different gender or different kinds of psychotherapies even within the psychoanalytic tradition. However, our novel approach for analyzing affective involvement and its regulation could be a useful method for studying other dyads and more sessions in the future.

In the current study we delineated in-session affect regulation, both self and interactive, as expressed in various linguistic variables of NP. Using variables of NP offers a potentially useful method for describing affective involvement of the client and therapist dyad, which can be applied to future studies of therapeutic interaction. Our method makes it possible to compare different affect regulation strategies used by various client-therapist dyads. 


\section{Acknowledgment}

This research was supported by NKFIH, the Hungarian National Research Foundation, under grant number PD 108868, 2013-2017.

\section{References}

Alpers, G. W., Wilhelm, F. H., \& Roth, W. T. (2005). Psychophysiological assessment during exposure in driving phobic patients. Journal of Abnormal Psychology, 114, 126-139.

Angus, L. E. \& McLeod, J. (2004). The handbook of narrative and psychotherapy: Practice, theory and research. Thousand Oaks, London, New Delhi: Sage.

Barclay, C. R. (1996). Autobiographical remembering: Narrative constraints on objectified selves. In D. C. Rubin (Ed.) Remembering our past: Studies in autobiographical memory (pp. 94-125) Cambridge, UK: Cambridge University Press.

Baumeister, R. F. \& Newman, L. S. (1994). How stories make sense of personal experiences: Motives that shape autobiographical narratives. Personality and Social Psychology Bulletin, 20, 676-690.

Berán, E. (2009). A narrativ perspektiva szabályozó szerepe a terápiás diskurzusban. Doktori disszertáció [The regulative role of narrative perspective in therapeutic discourse. Doctoral dissertation]. Budapest: ELTE, PPK.

Berán, E. \& Unoka, Z. (2005). Construction of self-narrative in a psychotherapeutic setting: An analysis of the mutual determination of narrative perspective taken by patient and therapist. In U. M. Quasthoff \& T. Becker (Eds.) Narrative interaction (pp. 151-168). Amsterdam/Philadelphia: John Benjamins Publishing Company.

Berán, E. \& Unoka, Z. (2012). A narratív perspektívaváltás figyelmi szabályozó szerepe a terápiás diskurzusban: két pszichoterápiás ülés részleteinek elemzése [The attention regulating role of shifting narrative perspective in therapeutic discourse: The analysis of two psychotherapeutic sessions]. Magyar Pszichológiai Szemle, 67, 467-490.

Berán, E., Unoka, Zs. (2015). Reconstructing anagency by shifting perspective in trauama narrative. Language and Psychoanalysis, 4, 50-74.

Berán, E., Unoka, Zs., \& Czobor, P. (2011). A szelf affektív bevonódása a pszichoterápiás folyamatba: érzelmi intenzitás kifejezése narratív perspektívahasználattal a terápia kezdeti szakaszában [Affective involevement of the self in the psychotherapeutic process: Expression of affect intesity in the use of various narrative perspectives at the beginning phase of therapy]. Pszichológia, 31, 237-257.

Berking, M., Wupperman, P., Reichardt, A., Pejic, T., Dippel, A., \& Znoj, H. (2008). Emotion-regulation skills as a treatment target in psychotherapy. Behaviour research and therapy, 46, 1230-1237.

Bradley, S. J. (2003). Affect regulation and the development of psychopathology. New York, NY: Guilford Press.

Bucci, W. (1995). The power of the narrative: A multiple code account. In Pennebaker, J. W. (Ed), Emotion, disclosure, \& health (pp. 93-122). Washington, DC: American Psychological Association.

Bucci, W. (2001). Pathways of emotional communication. Psychoanalytic Inquiry, 21, 40-70.

Language and Psychoanalysis, 2017, 6 (2), 76-98

http://dx.doi.org/10.7565/landp.v6i2.1573 
Buchheim, A. \& Mergenthaler, E. (2000). The relationship among attachment representation, emotion-abstraction patterns, and narrative style: A computerbased text analysis of the Adult Attachment Interview. Psychotherapy Research, 10, 390-407.

Chafe, W. (1994). Discourse, consciousness, and time. Chicago, London: The University of Chicago Press.

Cloitre, M., Stovall-McClough, K. C., Miranda, R., \& Chemtob, C. M. (2004). Therapeutic alliance, negative mood regulation, and treatment outcome in child abuse-related posttraumatic stress disorder. Journal of Consulting and Clinical Psychology, 72, 411-415.

Conway, M. A. (2009). Episodic memories. Neuropsychologia, 47, 2305-2313.

Conway, M. A. \& Pleydell-Pearce, C. W. (2000). The construction of autobiographical memories in the self-memory system. Psychological Review, 107, 261-288.

Dennett, D. C. (1989). The intentional stance. Cambridge, MA: MIT press.

Fletcher, P. C., Happe, F., Frith, U., Baker, S. C., Dolan, R. J., Frackowiak, R. S., Frith, C. D. (1995). Other minds in the brain: a functional imaging study of theory of mind in story comprehension. Cognition, 57, 109-128. doi:10.1016/0010-0277(95)00692-R

Fonagy, P. (2006). The mentalization-focused approach to social development. In J. G. Allen \& P. Fonagy (Eds.) Handbook of mentalization-based treatment, (pp. 53-100). West Sussex, UK: John Wiley \& Sons, Ltd.

Freud, S. (1959). Inhibitions, symptoms, anxiety (A. Strachey, Tran s. and J. Strachey, Ed.). New Yo rk: Norton . (Original work published 1926).

Gambini, O., Barbieri, V., \& Scarone, S. (2004). Theory of Mind in schizophrenia: First person vs third person perspective. Consciousness and Cognition, 13, 3946.

Garrod, S. \& Pickering, M. J. (2009). Joint action, interactive alignment, and dialog. Topics in Cognitive Science, 1, 292-304.

Gaston, L. (1990). The concept of the alliance and its role in psychotherapy: Theoretical and empirical considerations. Psychotherapy: Theory, Research, Practice, Training, 27, 143-153.

Genette, G. \& Lewin, J. E. (1983). Narrative discourse: An essay in method. Ithaka, NY: Cornell University Press.

Greenberg, L., \& Pascual-Leone, J. (1995). A dialectical constructivist approach to experiential change. In R.A. Neimeyer, \& M.J. Mahoney (Eds), Constructivism in psychotherapy (pp. 169-191). Washington, DC: American Psychological Association.

Gross, J. J. \& John, O. P. (1997). Revealing feelings: facets of emotional expressivity in self-reports, peer ratings, and behavior. Journal of personality and social psychology, 72, 435-448.

Habermas, T. (2006). Who speaks? Who looks? Who feels? Point of view in autobiographical narratives1. The International Journal of Psychoanalysis, 87, 497-518.

Habermas, T. \& Diel, V. (2010). The emotional impact of loss narratives: event severity and narrative perspectives. Emotion, 10, 312-323.

Jackson, P. L., Meltzoff, A. N., \& Decety, J. (2006). Neural circuits involved in imitation and perspective-taking. Neuroimage, 31, 429-439. 
Kenny, L. M., Bryant, R. A., Silove, D., Creamer, M., O'Donnell, M., \& McFarlane, A. C. (2009). Distant Memories A Prospective Study of Vantage Point of Trauma Memories. Psychological Science, 20, 1049-1052.

Koch, G. G., Carr, G. J., Amara, I. A., Stokes, M. E., and Uryniak, T. J. (1990). Categorical Data Analysis. In: D. A. Berry (Ed.) Statistical Methodology in the Pharmaceutical Sciences (pp. 391-475). New York: Marcel Dekker.

Kring, A. M. \& Sloan, D. M. (2007). The Facial Expression Coding System (FACES): development, validation, and utility. Psychological Assessment, 19, 210-224.

Kring, A. M., Smith, D. A., \& Neale, J. M. (1994). Individual differences in dispositional expressiveness: development and validation of the Emotional Expressivity Scale. Journal of Personality and Social Psychology, 66, 934949.

Levy, K. N., Meehan, K. B., Kelly, K. M., Reynoso, J. S., Weber, M., Clarkin, J. F., Kernberg, O. (2006). Change in attachment patterns and reflective function in a randomized control trial of transference-focused psychotherapy for borderline personality disorder. Journal of Consulting and Clinical Psychology, 74, 1027-1040.

Liang, K.-Y., and Zeger, S. L. (1986). Longitudinal Data Analysis Using Generalized Linear Models. Biometrika, 73, 13-22.

Lin, X., and Breslow, N. E. (1996). Bias Correction in Generalized Linear Mixed Models with Multiple Components of Dispersion. Journal of the American Statistical Association, 91, 1007-1016.

Luborsky, L. (1977). Measuring a pervasive psychic structure in psychotherapy: The core conflictual relationship theme. In N. Freedman \& S. Grand (Eds.) Communicative structures and psychic structures: A psychoanalytic interpretation of communication (pp. 367-395). New York, NY: Springer Science + Business Media LLC.

Luborsky, L. (1976). Helping alliances in psychotherapy. In J. L. Cleghhorn (Ed.), Successful psychotherapy (pp. 92-116). New York: Brunner/Mazel.

MacWhinney, B. (2005). The emergence of grammar from perspective. In J. W. Minett \& W. S-Y. Wang (Eds.) Language Acquisition, Change and Emergence: Essays in Evolutionary Linguistics (pp. 95-150). Hong Kong: City University of Hong Kong Press.

MacWhinney, B. \& Snow, C. (1990). The child language data exchange system: An update. Journal of Child Language, 17, 457-472.

McIsaac, H. K. \& Eich, E. (2002). Vantage point in episodic memory. Psychonomic Bulletin \& Review, 9, 146-150.

McIsaac, H. K. \& Eich, E. (2004). Vantage point in traumatic memory. Psychological Science, 15, 248-253.

Mergenthaler, E. (2004). Emotional cognitive and behavioral changes in a single case study: An application of the therapeutic cycles model. In 35th Annual Meeting of the Society for Psychotherapy Research, Rome, Italy.

Mergenthaler, E. (1996). Emotion-abstraction patterns in verbatim protocols: A new way of describing psychotherapeutic processes. Journal of Consulting and Clinical Psychology, 64, 1306-1315.

Missirlian, T. M., Toukmanian, S. G., Warwar, S. H., \& Greenberg, L. S. (2005). Emotional arousal, client perceptual processing, and the working alliance in experiential psychotherapy for depression. Journal of Consulting and Clinical Psychology, 73, 861-871.

Language and Psychoanalysis, 2017, 6 (2), 76-98

http://dx.doi.org/10.7565/landp.v6i2.1573 
Nelson, K. \& Fivush, R. (2004). The emergence of autobiographical memory: a social cultural developmental theory. Psychological Review, 111, 486-511.

Németh, T. E. (1996). A szóbeli diskurzusok megnyilatkozás példányokra tagolása. [Segmenting verbal discourse into utterance units]. Budapest: Akadémia Kiadó.

Owens, K. A., Haddock, G., \& Berry, K. (2013). The role of the therapeutic alliance in the regulation of emotion in psychosis: an attachment perspective. Clinical psychology \& psychotherapy, 20, 523-530.

Perakyla, A., Antaki, C., Vehvilainen, S., \& Leudar, I. (Eds.) (2008). Conversation analysis and psychotherapy. Cambridge, UK: Cambridge University Press.

Pillemer, D. B., Desrochers, A. B., \& Ebanks, C. M. (1998). Remembering the past in the present: Verb tense shifts in autobiographical memory narratives. In C.P.E.Thompson, D. J. E. Herrmann, D. E. Bruce, J. D. E. Read, D. G. E. Payne, \& M. P. E. Toglia (Eds.), Autobiographical memory: Theoretical and applied perspectives (pp. 145-162). Mahwah, NJ: Lawrence Erlbaum Associates Publishers.

Pólya, T., Kis, B., Naszódi, M., \& László, J. (2007). Narrative perspective and the emotion regulation of a narrating person. Empirical Text and Culture Research, 7, 50-61.

Pos, A. E., Greenberg, L. S., Goldman, R. N., \& Korman, L. M. (2003). Emotional processing during experiential treatment of depression. Journal of Consulting and Clinical Psychology, 71, 1007-1017.

Price, P. B. \& Jones, E. E. (1998). Examining the alliance using the Psychotherapy Process Q-Set. Psychotherapy: theory, research, practice, training, 35, 392404.

Raes, F., Hermans, D., de Decker, A., Eelen, P., Williams, J. M. \& Mark, G. (2003). Autobiographical memory specificity and affect regulation: an experimental approach. Emotion, 3, 201-206.

Rice, H. J. \& Rubin, D. C. (2009). I can see it both ways: First-and third-person visual perspectives at retrieval. Consciousness and Cognition, 18, 877-890.

Robinson, M. D. \& Clore, G. L. (2002). Belief and feeling: evidence for an accessibility model of emotional self-report. Psychological Bulletin, 128, 934960.

Sabatinelli, D., Lang, P. J., Bradley, M. M., \& Flaisch, T. (2006). The neural basis of narrative imagery: emotion and action. Progress in Brain Research, 156, 93103.

Schiffrin, D. (1981). Tense variation in narrative. Language, 57, 45-62.

Sloan, D. M. \& Kring, A. M. (2007). Measuring changes in emotion during psychotherapy: Conceptual and methodological issues. Clinical Psychology: Science and Practice, 14, 307-322.

Sutin, A. R. \& Robins, R. W. (2008). When the 'I' looks at the 'Me': Autobiographical memory, visual perspective, and the self. Consciousness and Cognition, 17, 1386-1397.

Tannen, D. (1989). Talking voices: Repetition, dialogue, and imagery in conversational discourse. Cambridge, UK: Cambridge University Press.

Thoma, H. \& Kachele, H. (2006). Psychoanalytische Therapie: Grundlagen. Berlin, Germany: Springer Medizin Verlag.

Uspensky, B. (1973). A poetics of composition: The structure of the artistic text and typology of a compositional form. Berkeley, CA: University of California Press.

Language and Psychoanalysis, 2017, 6 (2), 76-98

http://dx.doi.org/10.7565/landp.v6i2.1573 
Wallerstein, R. (1988). Assessment of structural change in psychoanalytic therapy and research. Journal of the American Psychoanalytic Association, 36, 241-261.

Wallerstein, R. S. (2005). Outcome research. In ES Person, AM Cooper, GO Gabbard (Eds.), The American Psychiatric Publishing Textbook of Psychoanalysis (pp 301-315). Washington, DC: American Psychiatric Publishing, Inc.

Watson, D., Clark, L. A., \& Tellegen, A. (1988). Development and validation of brief measures of positive and negative affect: the PANAS scales. Journal of Personality and Social Psychology, 54, 1063-1070.

Watson, J. C., \& Greenberg, L. S. (1996). Pathways to change in the psychotherapy of depression: Relating process to session change and outcome. Psychotherapy: Theory, Research, Practice, Training, 33, 262-274.

Watson, J. C., Greenberg, L. S., \& Lietaer, G. (1998). The experiential paradigm unfolding: Relationship and experiencing in therapy. In L. S. Greenberg, J. C. Watson, \& G. Lietaer (Eds.), Handbook of experiential psychotherapy, pp. 327. New York: Guilford Press.

Watson, J. C., McMullen, E. J., Prosser, M. C., \& Bedard, D. L. (2011). An examination of the relationships among clients' affect regulation, in-session emotional processing, the working alliance, and outcome. Psychotherapy Research, 21, 86-96.

Wolfson, N. (1979). The conversational historical present alternation. Language, 55, 168-182. 